\title{
Insulin-like Growth Factor II Messenger RNA-binding Protein 3 in Salivary Gland Tumors
}

\author{
Adna B. Ismerim, MSc,* Stephany V. Ferreira, DDS, $\dagger$ Anne M.G. Lessa, DDS, $\dagger$ \\ Aderbal S. Pereira Júnior, DDS, $\dagger$ Clarissa A. Gurgel, PhD,*† \\ Claudia M. Coutinho-Camillo, PhD, § Fernando A. Soares, PhD, $\S$ Deise S. Vilas-Bôas, PhD, ॥ \\ Manuela T.A. Vidal, MSc, $\$$ and Jean N.d. Santos, PhD* +
}

\begin{abstract}
Insulin-like growth factor II mRNA-binding protein 3 (IMP3) is strongly expressed in malignant tumors and has been associated with their aggressive behavior. The aim of this study was to evaluate the presence of IMP3 in a series of salivary gland tumors. The sample consisted of 9 pleomorphic adenomas (PA), 14 adenoid cystic carcinomas (ACC), and 13 mucoepidermoid carcinomas (MEC) that were investigated by immunohistochemical technique. All cases of PA and MEC were positive for IMP3 particularly in the cytoplasm. PA showed 4 cases as high expression and 6 as low expression. MEC showed 10 cases as low expression and 3 as high expression. For ACC, 4 cases were high expression, whereas 6 cases were low expression. No significant difference was observed between tumors $(P>0.05$, Fisher's test) when both scores of IMP3 were compared. This study showed that MEC seems to be more sensitive to IMP3 than ACC and provided an insight into this protein in salivary gland tumors. Furthermore, although IMP3 is not a specific diagnostic marker to distinguish the tumors studied, it seems to mediate cell adhesion and migration in these tumors. Further studies should be performed to better understand the IMP3 biology in salivary gland tumors.
\end{abstract}

Key Words: insulin-like growth factor II, malignant tumor, salivary cancer, immunohistochemistry

(Appl Immunohistochem Mol Morphol 2016;24:422-426)

S alivary gland tumors comprise a diverse group of benign and malignant tumors with different morphologic and behavioral characteristics, ${ }^{1}$ including propensity

Received for publication January 19, 2015; accepted March 11, 2015. From the *Dentistry and Health Post Graduation Program, School of Dentistry, Federal University of Bahia; $†$ School of Dentistry, Federal University of Bahia; \#Department of Biomorphology, Institute of Health Sciences, Federal University of Bahia Salvador, Bahia; Laboratory of Oral Surgical Pathology, School of Dentistry, Federal University of Bahia and Human Pathology Postgraduation Program, Fiocruz, Salvador, Bahia; and §A.C. Camargo Center Cancer, São Paulo-SP, Brazil.

The authors declare no conflict of interest.

Reprints: Jean N. Santos, PhD, Laboratório de Patologia Cirúrgica, UFBA, Avenida Araújo Pinho, 62, Canela, Salvador, Bahia 40110150, Brasil (e-mail: jeanunes@ufba.br).

Copyright (C) 2015 Wolters Kluwer Health, Inc. All rights reserved. for recurrence ${ }^{2}$ and metastasis. ${ }^{3}$ The histologic diversity of these tumors has been attributed to the presence of myoepithelial cells, ${ }^{4}$ with tumors containing myoepithelial cells exhibiting slow progression and a low metastatic capacity. ${ }^{5,6}$ Therefore, different markers have been studied in an attempt to distinguish these tumors.

Insulin-like growth factor II mRNA-binding protein 3 (IMP3), an mRNA-binding protein belonging to the insulin-like growth factor II family, is an oncofetal protein that is expressed in fetal and cancer tissues. ${ }^{7}$ This protein consists of 580 amino acid residues and is encoded by an mRNA transcript of 4350 nucleotides. ${ }^{8}$ The gene encoding IMP3 is located on chromosome $7 \mathrm{p} 15$ and plays an important role in the migration and adhesion of cells in different malignant neoplasms. ${ }^{8}$ Furthermore, this protein is involved in the posttranscriptional regulation of cell proliferation during embryogenes. ${ }^{9}$ So far, 3 members of this family are known: IMP1, IMP2, and IMP $3 .{ }^{8,10}$ IMP3 is strongly expressed in malignant tumors, but rarely in normal adult tissues. ${ }^{11}$ Many authors have demonstrated the expression of IMP3 in a variety of human tumors, including carcinomas and adenocarcinomas. ${ }^{7,12-23}$

Despite the frequency, malignant salivary gland tumors are rare $^{2}$ but have raised interest on the part of various researchers. To our knowledge, there are no studies investigating IMP3 in salivary gland tumors. Therefore, as IMP3 is an important biomarker of aggressive tumors, the objective of the present study was to evaluate the presence of this protein in a series of salivary gland tumors.

\section{METHODS}

After approval by the Ethics Committee of the School of Dentistry, Federal University of Bahia, Salvador, Bahia, Brazil, 36 salivary gland tumors were studied. The sample consisted of 9 pleomorphic adenomas (PA), 14 adenoid cystic carcinomas (ACC), and 13 mucoepidermoid carcinomas (MEC). The cases were retrieved from the Archives of the Pathological Anatomy Service, School of Dentistry, Federal University of Bahia. The histopathologic diagnosis was revised and classified by an experienced oral pathologist (J.N.S.) based on the current World Health Organization classification. ${ }^{24}$ Clinical data obtained from the request forms of the anatomopathologic examinations 
showed that 21 patients were females and 15 were males. The mean age was 41.7 years.

Sections $(3 \mu \mathrm{m})$ cut from paraffin-embedded specimens were deparaffinized in xylene (2 times for $10 \mathrm{~min}$ ) and absolute alcohol ( 2 times for $5 \mathrm{~min}$ ) at room temperature. Antigen retrieval was performed by boiling the sections in Tris/EDTA solution, $\mathrm{pH}$ 9, for 30 minutes at $98^{\circ} \mathrm{C}$. Endogenous peroxidase activity was blocked by immersion of the tissue sections in phosphate-buffered saline containing $0.3 \%$ hydrogen peroxide. Next, the sections were incubated with the primary antibody (antiIMP3, clone 69.1, Dako, Carpinteria, CA) diluted in antibody diluent plus background-reducing components (Dako Corporation) at 4 room temperature, for $30 \mathrm{mi}-$ nutes. The polymer (Advance, Dako) was then applied for 30 minutes at room temperature. The reaction was developed with 3,3-diaminobenzidine (Dako) as chromogen solution for 5 minutes in a dark chamber. The sections were counterstained with Harris hematoxylin. Finally, the sections were dehydrated in absolute alcohol, cleared in xylene, and mounted. Placental tissue was used as positive control. The negative control consisted of replacement of the primary antibody with normal serum of the same isotype as the primary antibody.

Positive cases were identified by brown staining in the cytoplasm and the nucleus of cells and scored as follows: score 0 , no staining; score 1 , weak staining; score 2 , moderate staining; and score 3, strong staining. The proportion of staining was defined as the percentage of stained cells $(0,0 \%$; $1,1 \%$ to $25 \% ; 2,25 \%$ to $75 \%$; and $3,>75 \%$ ). Multiplication of the staining intensity ( 0 to 3 ) by proportion $(0 \%$ to $>75 \%$ ) resulted in the following score: the product of the 2 scores was up to 3 when $<25 \%$ of the cells were stained or the immunostaining intensity was weak, and expression was classified as low. The product of the 2 scores was $\geq 4$ when at least $25 \%$ of the cells were stained and the immunostaining intensity was moderate or strong, and expression was classified as high, adapted from Dultra et al. ${ }^{25}$

Differences between groups were tested using the Fisher test. All statistical calculations were performed using the GraphPad Prism 5.0 program (San Diego). A Pvalue $<0.05$ was considered to be statistically significant.

\section{RESULTS}

The immunohistochemical scores are summarized in Table 1.

\section{Pleomorphic Adenoma}

All cases of PA $(n=9)$ were positive for IMP3 particularly in the cytoplasm. Staining was heterogenous and only 2 cases were classified as high expression. Marked staining was mainly observed in areas of squamous metaplasia. However, the nuclei of myoepithelial cells and the cytoplasm of some of these cells were also positive. Staining for IMP3 was also detected in luminal cells of ductal structures (Figs. 1A, B).
TABLE 1. Distribution of Salivary Glands Tumors Studied and Their Immunohistochemical Scores

\begin{tabular}{lcc}
\hline & \multicolumn{2}{c}{ Score } \\
\cline { 2 - 3 } Tumors & $\begin{array}{c}\text { Low Expression } \\
\mathbf{( \% )}\end{array}$ & $\begin{array}{c}\text { High Expression } \\
(\mathbf{\%})\end{array}$ \\
\hline Pleomorphic adenoma & 77.7 & 22.3 \\
Adenoid cystic carcinoma & 42.8 & 28.6 \\
Mucoepidermoid & 23.1 & 76.9 \\
carcinoma & & \\
\hline
\end{tabular}

\section{Adenoid Cystic Carcinoma}

Staining was heterogenous. Among positive cases, high expression was observed in 4 and low expression in 6 . In these tumors, cytoplasmic, membranous, and nuclear staining was detected in cribriform and solid areas and in more internal cells of tubular and tubulotrabecular structures. Only 4 of the 14 cases of ACC were negative for IMP3 (Figs. 1C-F).

\section{Mucoepidermoid Carcinoma}

Although staining was also heterogenous, all MEC cases were positive for IMP3, with the observation of cytoplasmic staining in areas corresponding to squamous and intermediate cells. Cytoplasmic granular staining was observed in many cases. Mucosal cells were negative. Among the 13 IMP3-positive cases, 3 were classified as high expression and 10 as low expression (Figs. 1G, H).

\section{Normal Salivary Gland}

In the normal salivary gland, IMP3 staining was positive in the cytoplasm of luminal and extraluminal cells of the ductal segment, including striated and excretory ducts. In the intercalated duct, staining was also observed in the cytoplasm of luminal cells (Fig. 1).

\section{Comparison Between Tumors}

No significant association was observed between tumors $(P>0.05)$ when these scores (low and high) were compared.

\section{DISCUSSION}

To the best of our knowledge, this is the first study investigating the expression of IMP 3 in tumors derived from different segments of the morphofunctional unit of the salivary gland. This study showed the expression of IMP3 in the cytoplasm of MEC and ACC, although some cell nuclei were also stained in cases of PA and ACC.

IMP3 is found in developing tissues during embryogenesis where it plays an important role in RNA trafficking and stabilization as well as in cell growth and migration. ${ }^{26}$ The expression of IMP3 is low or undetectable in adult tissues, but the protein is strongly expressed in malignant tumors and has been associated with the aggressive behavior of different tumors, poor differentiation, advanced stage, and unfavorable prognosis. ${ }^{9} 11,12,15,17-23,27,28$ In the present study, similar to the salivary gland tumors studied, the cytoplasm of normal salivary duct cells was also positive for IMP3. 

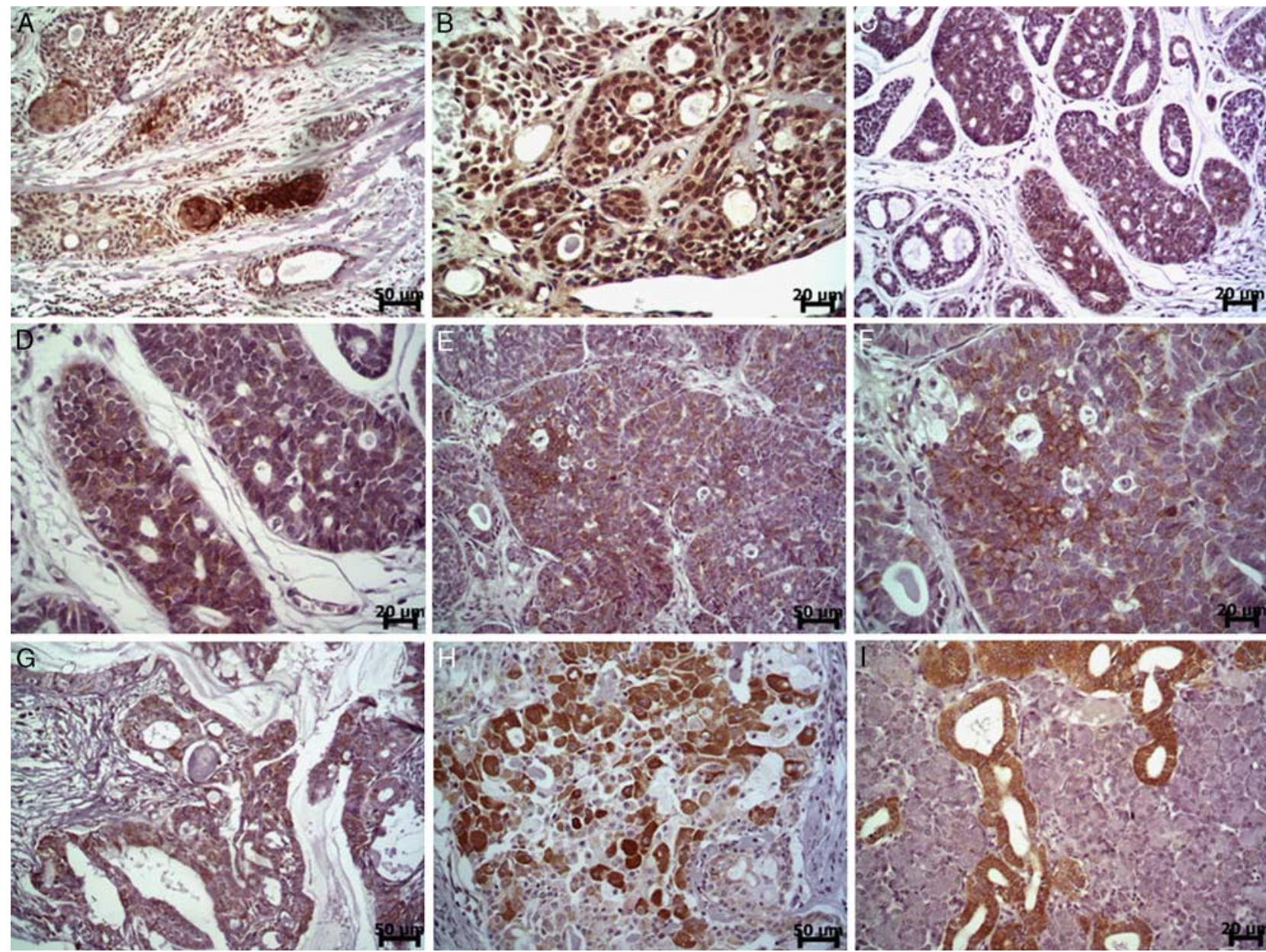

FIGURE 1. A, Pleomorphic adenoma: ductal and myoepithelial cells with immunohistochemical staining predominantly granular and cytoplasmatic and variable intensity in areas displaying squamous differentiation. B, Pleomorphic adenoma: myoepithelial cells with immunohistochemical staining predominantly nuclear. C, Cribriform cystic adenoid carcinoma: parenchyma showing loss of immunohistochemical staining. D, Cribriform adenoid cystic carcinoma: high-power view showing cytoplasmatic immunohistochemical staining especially in areas with luminal differentiation. E, Adenoid cystic carcinoma: solid areas showing membranous and cytoplasmatic immunohistochemical staining. F, Adenoid cystic carcinoma: high-power showing immunohistochemical staining predominantly membranous. G, Mucoepidermoid carcinoma: papillary cystic growth showing some cuboidal and columnar cells with cytoplasm immunostained. $H$, Variable immunohistochemical staining in the cytoplasm of epidermoid cells. I, Normal salivary gland: granular and cytoplasmatic immunohistochemical staining in ductal segment.

However, these findings seem to differ from human breast tissue that did not show positivity for IMP $3,{ }^{29}$ but are similar to a study showing IMP3 staining in germinal center cells of reactive lymph nodes and normal tonsils, as well as in follicular lymphoma. ${ }^{11}$ With respect to the positive cell nuclei found in PAs and ACC, Li et al ${ }^{13}$ also detected IMP3-positive nuclei in oral squamous cell carcinomas. This finding might be explained by the posttranscriptional regulation of mRNA whose proteins can be located in both the cytoplasm and the nucleus. ${ }^{30,31}$

The present results showed expression of IMP3 in all MEC, although this expression was low in $77 \%$ of cases. A similar result was obtained for PAs, in which all cases were positive for IMP3, but expression was low in $77.7 \%$ of cases. In contrast, in ACC, expression of this protein was observed in slightly more than $57 \%$ of cases, with low and high expression in $28 \%$ each. Although we were not able to demonstrate differences between benign tumors and malignant ones and MEC and ACC, these findings seems to suggest that IMP3 staining differs between these tumors, permitting us to hypothesize that this protein is an important biomarker of salivary tumors with squamous differentiation, although it is not specific to distinguish the complex histopathology of salivary gland tumors. Regarding this hypothesis, some studies have demonstrated the expression of this protein in squamous cell carcinomas, $28,32,33$ including head and neck carcinomas. ${ }^{22,30,31,34}$

Furthermore, there seems to be a loss of IMP3, especially in cases of ACC. A previous study from our group has shown heterogenous staining for E-cadherin in 
a series of salivary gland tumors and loss of immunostaining for this protein was also observed in ACC. ${ }^{25}$ In an extensive review of a large series of different malignant human cancers, excluding salivary gland tumors, Findeis-Hosey and $\mathrm{Xu}^{7}$ observed variable positive expression of this protein. Soddu et $\mathrm{al}^{33}$ also reported heterogenous immunostaining for IMP3.

Although the salivary carcinomas studied here exhibited different grades of malignancy, it was not possible to make a distinction as most MECs of the sample were low grade; however, 3 of the low-grade MEC showed high expression of IMP3, whereas more than $70 \%$ of the ACC cases were of the cribriform type. Nevertheless, these findings demonstrate that IMP3 plays a key role in the development of these tumors. However, further studies involving larger series of these rare tumors and comparing different clinical parameters are needed to clarify the role of IMP 3 in tumors with different grades of malignancy. It should be noted that this is a preliminary study and several authors have shown different functions of this protein related to tumor behavior and progression. In this respect, some authors have associated IMP3 with tumor invasion, ${ }^{35}$ cell migration, ${ }^{36}$ and metastatic potential, ${ }^{12,27}$ whereas others demonstrated its role in the regulation of cell proliferation. ${ }^{27,32}$ IMP3 has also been shown to be an important prognostic marker, ${ }^{27,31}$ and has been indicated as a therapeutic target. ${ }^{37}$ A recent study demonstrated a regulatory role of IMP3 in cancer cells with stem-cell properties. ${ }^{37}$

It was not possible in the present study to establish the usefulness of IMP3 as a diagnostic marker that could distinguish the different tumors studied. Jeng et al, ${ }^{27}$ showed that depletion of IMP3 with interference RNA in a hepatocellular carcinoma cell line caused a reduction in cell motility, invasion, and transendothelial migration. We therefore believe that IMP3 is involved in cell adhesion and migration in salivary gland tumors.

Finally, this study showed that MEC seems to be more sensitive to IMP3 than ACC and provided an insight into this protein in salivary gland tumors. Furthermore, although IMP3 is not a specific diagnostic marker to distinguish the tumors studied, it seems to mediate cell adhesion and migration in these tumors. Further studies should be performed to better understand the IMP3 biology in salivary gland tumors.

\section{ACKNOWLEDGMENT}

The authors thanks CNPq and FAPESB for financial support and scholarships.

\section{REFERENCES}

1. Ogawa AI, Takemoto LE, Navarro PL, et al. Neoplasias de Glândulas Salivares. Arq Int Otorrinolaringol/Intl Arch Otorhinolaryngol. 2008;12:409-418.

2. Barros AC, Gurgel CAS, Gomes MC, et al. Minor salivary gland tumors in a south American population. Arch Oncol. 2010;18:56-59.

3. Venteicher AS, Walcott BP, Sheth SA, et al. Clinical features of brain metastasis from salivary gland tumors. $J$ Clin Neurosci. 2013;20:1533-1537.

4. Raitz R, Araújo VC. Diferenciação mioepitelial nas neoplasias de glândula salivar. Acta Scientiarum. Health Sci. 2004;26:345-350.
5. Barsky S, Karlin N. Myoepithelial cells: autocrine and paracrine suppressors of breast cancer progression. J Mammary Gland Biol Neoplasia. 2005;10:249-260.

6. Costa AF, Demasi AP, Bonfitto VL, et al. Angiogenesis in salivary carcinomas with and without myoepithelial differentiation. Virchows Arch. 2008;453:359-367.

7. Findeis-Hosey JJ, Xu H. The use of insulin like-growth factor II messenger RNA binding protein-3 in diagnostic pathology. Hum Pathol. 2011;42:303-314.

8. Nielsen J, Christiansen J, Lykke-Andersen J, et al. A family of insulin-like growth factor II mRNA-binding proteins represses translation in late development. Mol Cell Biol. 1999;19: $1262-1270$.

9. Wang L, Li H, Xia Z, et al. IMP3 is a novel biomarker to predict metastasis et prognosis of gastric adenocarcinoma: a retrospective study. Chin Med J. 2010;123:3554-3558.

10. Liao B, Hu Y, Herrick DJ, et al. The RNA-binding protein IMP-3 is a translational activator of insulin-like growth factor II leader-3 mRNA during proliferation of human K562 leukemia cells. J BiolChem. 2005;280:18517-18524.

11. King RL, Pasha T, Roullet MR, et al. IMP-3 is differentially expressed in normal and neoplastic lymphoid tissue. Hum Pathol. 2009:40:1699-1705.

12. Jiang Z, Chu PG, Woda BA, et al. Analysis of RNA-binding protein IMP3 to predict metastasis and prognosis of renal-cell carcinoma: a retrospective study. Lancet Oncol. 2006;7:556-564.

13. Li C, Zota V, Woda BA, et al. Expression of a novel oncofetal mRNA-binding protein IMP3 in endometrial carcinomas: diagnostic significance and clinicopathologic correlations. Mod Pathol. 2007;20:1263-1268.

14. Wachter DL, Kristiansen G, Soll C, et al. Insulin-like growth factor II mRNA-binding protein 3 (IMP3) expression in hepatocellular carcinoma. A clinicopathological analysis with emphasis on diagnostic value. Histopathology. 2012;60:278-286.

15. Ikenberg K, Fritzsche FR, Zuerrer-Haerdi U, et al. Insulin-like growth factor II mRNA binding protein 3 (IMP3) is overexpressed in prostate cancer and correlates with higher Gleason scores. $B M C$ Cancer. 2010;10:341-346.

16. Schaeffer DF, Owen DR, Lim HJ, et al. Insulin-like growth factor 2 mRNA binding protein 3 (IGF2BP3) overexpression in pancreatic ductal adenocarcinoma correlates with poor survival. BMC Cancer. 2010;10:59-66.

17. Yuan RH, Wang CC, Chou CC, et al. Diffuse expression of RNAbinding protein IMP3 predicts high-stage lymph node metastasis and poor prognosis in colorectal adenocarcinoma. Ann Surg Oncol. 2009;16:1711-1719.

18. Gao Y, Yang M, Jiang Z, et al. IMP3 expression is associated with poor outcome and epigenetic deregulation in intrahepatic cholangiocarcinoma. Human Pathol. 2014;45:1184-1191.

19. Gong Y, Woda BA, Jiang Z. Oncofetal protein IMP3, a new cancer biomarker. Adv Anat Pathol. 2014;21:191-200.

20. Trivedi A, Cartun RW, Ligato S. Role of lymphovascular invasion and immunohistochemical expression of IMP3 in the risk stratification of superficially invasive pT1 esophageal adenocarcinoma. Pathol Res Pract. 2014;210:402-406.

21. Szarvas T, vomDorp F, Niedworok C, et al. High insulin-like growth factor mRNA-binding protein 3 (IMP3) protein expression is associated with poor survival in muscle-invasive bladder cancer. BJU Int. 2012;110:E308-E3017.

22. Kim KY, Li S, Cha JD, et al. Significance of molecular markers in survival prediction of oral squamous cell carcinoma. Head Neck. 2012;34:929-936.

23. Yamamoto H, Arakaki K, Morimatsu K, et al. Insulin-like growth factor II messenger RNA-binding protein 3 expression in gastrointestinal mesenchymal tumors. Hum Pathol. 2014;45: 481-487.

24. Barnes L, Eveson JW, Reichart P, et al. World Health Organization Classification of Tumours. Lyon: Pathology and Genetics of Head and Neck Tumours IARC; 2005.

25. Dultra FK, Barros AC, Schaer-Barbosa H, et al. Immunohistochemical assessment of CDlapositive Langerhans cells and their 
relationship with Ecadherin in minor salivary gland tumors. J Oral Pathol Med. 2012;41:47-53.

26. Mueller-Pillasch F, Pohl B, Wilda M, et al. Expression of the highly conserved RNA binding protein KOC in embryogenesis. Mech Dev. 1999;88:95-99.

27. Jeng YM, Chang CC, Hu FC, et al. RNA-binding protein insulinlike growth factor II mRNA-binding protein 3 expression promotes tumor invasion and predicts early recurrence and poor prognosis in hepatocellular carcinoma. Hepatology. 2008;48:1118-1127.

28. Lin L, Zhang J, Wang Y, et al. Insulin-like growth factor-II mRNAbinding protein 3 predicts a poor prognosis for colorectal adenocarcinoma. Oncol Lett. 2013;6:740-744.

29. Walter O, Prasad M, Lu S, et al. IMP3 is a novel biomarker for triple negative invasive mammary carcinoma associated with a more aggressive phenotype. Hum Pathol. 2009;40:1528-1533.

30. Chromecki TF, Cha EK, Pummer K, et al. Prognostic value of insulin-like growth factor II mRNA binding protein 3 in patients treated with radical prostatectomy. BJU Int. 2012;110:63-68.

31. Clauditz TS, Wang CJ, Gontarewicz A, et al. Expression of insulinlike growth factor II mRNA-binding protein 3 in squamous cell carcinomas of the head and neck. J Oral Pathol Med. 2013;42: 125-132.

32. Chen K, Cornejo KM, Ye W, et al. Oncofetal protein IMP3: a new diagnostic biomarker for laryngeal carcinoma. Hum Pathol. 2013;44: 2126-2131

33. Soddu S, Di Felice E, Cabras S, et al. IMP-3 expression in keratoacanthomas and squamous cell carcinomas of the skin: an immunohistochemical study. Eur J Histochem. 2013;57:e6.

34. Li S, Cha J, Kim J, et al. Insulin-like growth factor II mRNAbinding protein 3: a novel prognostic biomarker for oral squamous cell carcinoma. Head Neck. 2011;33:368-374.

35. Vikesaa J, Hansen TV, Jonson L, et al. RNA-binding IMPs promote cell adhesion and invadopodia formation. EMBO J. 2006;25: 1456-1468.

36. Yaniv K, Fainsod A, Kalcheim C, et al. The involvement of a conserved family of RNA binding proteins in embryonic development and carcinogenesis. Gene. 2002;287:49-54.

37. Ueki A, Shimizu T, Masuda K, et al. Up-regulation of Imp3 confers in vivo tumorigenicity on murine osteosarcoma cells. PLoS One. 2012;7:e50621 